\title{
The Origin of Inlet Buzz in a Mach 1.7 Low Boom Inlet Design
}

\author{
Bernhard H. Anderson* \\ NASA Glenn Research Center \\ Cleveland, Ohio, 44135 \\ and \\ Lois Weir** \\ TechLand Research, Inc. \\ North Olmsted, Ohio, 44070
}

\begin{abstract}
Supersonic inlets with external compression, having a good level performance at the critical operating point, exhibit a marked instability of the flow in some subcritical operation below a critical value of the capture mass flow ratio. This takes the form of severe oscillations of the shock system, commonly known as "buzz". The underlying purpose of this study is to indicate how Detached Eddy Simulation (DES) analysis of supersonic inlets will alter how we envision unsteady inlet aerodynamics, particularly inlet buzz. Presented in this paper is a discussion regarding the physical explanation underlying inlet buzz as indicated by DES analysis. It is the normal shock wave boundary layer separation along the spike surface which reduces the capture mass flow that is the controlling mechanism which determines the onset of inlet buzz, and it is the aerodynamic characteristics of a choked nozzle that provide the feedback mechanism that sustains the buzz cycle by imposing a fixed mean corrected inlet weight flow. Comparisons between the DES analysis of the Lockheed Martin Corporation (LMCO) $\mathrm{N}+2$ inlet and schlieren photographs taken during the test of the Gulfstream Large Scale Low Boom (LSLB) inlet in the NASA $8 \times 6 \mathrm{ft}$. Supersonic Wind Tunnel (SWT) show a strong similarity both in turbulent flow field structure and shock wave formation during the buzz cycle. This demonstrates the value of DES analysis for the design and understanding of supersonic inlets.
\end{abstract}

\section{NOMENCLATURE}

$\begin{array}{ll}\text { A } & \text { Survey Station Area } \\ \text { AIP } & \text { Aerodynamic Interface Plane } \\ \text { C-D } & \text { Convergent-Divergent } \\ \text { CFD } & \text { Computational Fluid Dynamics } \\ \text { D }_{\text {AIP }} & \text { AIP Diameter } \\ \text { DES } & \text { Detached Eddy Simulation } \\ \text { GAC } & \text { Gulfstream Aerospace Corporation } \\ \text { L } & \text { Inlet Diffuser Length } \\ \text { LMCO } & \text { Lockheed Martin Company }\end{array}$

* Aerospace Engineer, NASA Glenn Research Center, Cleveland, Ohio, 44135

** Aerospace Engineer, Techland Research Inc., North Olmsted, Ohio, 44070 


\begin{tabular}{ll} 
MAIP & \multicolumn{1}{c}{ Survey Station Average Mach Number } \\
$\mathrm{M}_{0}$ & Free Stream Mach Number \\
PFAIP & Inlet AIP Total Pressure Recovery \\
$\mathrm{P}_{\text {ref }}$ & Standard Sea Level Total Pressure \\
$\mathrm{P}_{0}$ & Tunnel Total Pressure \\
$\mathrm{R}$ & Gas Constant \\
$\mathrm{Re}$ & Reynolds Number per ft. \\
$\mathrm{Rev}$ & Revolution of the Fan \\
$\mathrm{RPM}$ & Revolutions per Minute \\
$\mathrm{Sec}$ & Seconds \\
$\mathrm{SWBL}$ & Shock Wave Boundary Layer \\
$\mathrm{T}_{\text {ref }}$ & Standard Sea Level Total Temperature \\
$\mathrm{T}_{0}$ & Tunnel Total Temperature \\
$w$ & Inlet Weight Flow \\
$\alpha$ & Inlet Angle-of-Incidence \\
$\beta$ & Inlet Angle-of-Yaw \\
$\delta$ & Total Pressure Ratio, P/P ref \\
$\Delta t$ & Relative Time \\
$\gamma$ & Ratio of Specifics Heats \\
$\theta$ & Total Temperature Ratio, T/T ref \\
$\theta$ & Conical Half Angle
\end{tabular}

\section{INTRODUCTION}

All supersonic inlets with external compression, having a good level performance at the critical operating point, exhibit a marked instability of the flow in some subcritical operation below a critical value of the capture mass flow ratio. This takes the form of severe oscillations of the shock system, commonly known as "buzz". This phenomenon was first described by Oswatitch $^{(1)}$ in experiments on axisymmetric inlets with conical forebodies. It received a great deal of experimental attention on similar configurations throughout the 1950's, both in the US and Britain. With the advent of rectangular inlets in the 1960's for both civil and military vehicles with variable geometry, the importance of the inlet buzz phenomenon to practical design diminished. The reason for this diminished interest in inlet buzz lies in the fact that the acceptable subcritical stability margins could be achieved with rectangular inlets before buzz occurred. However, the problem of inlet buzz still retains considerable intrinsic interest and a basic practical importance because it is tied to the prediction (estimation) of the inlet subcritical stability margin.

The intrinsic interest in the inlet buzz phenomenon is centered on two basics questions, (1) what is the triggering instability that initiates the inlet buzz cycle?, and (2) what is the aerodynamic mechanism that sustains inlet buzz? Ferri and Nucci ${ }^{(2)}$ observed experimentally, in a large number of cases, that shock oscillations commenced when the vortex sheet from the intersection point of the normal and oblique shocks moved across the cowl lip from outside to inside. This occurrence is generally known in the inlet design world as the "Ferri Criteria" The instability cycle proposed by Ferri and Nucci involved choking in the subsonic diffuser as a result of unsteady flow separation on the cowl. Whatever may be the precise details of the 
oscillation cycle, there is no doubt that the entry of the vortex sheet within the cowl boundary layer can trigger instabilities in axisymmetric conical inlets typical of the 1950's. But the forebody flow field of the LMCO N+2 inlet (the object of this investigation) is decidedly different than the flow field of a conical inlet typical of the 1950's. It is an isentropic spike design, where the Mach number along the spike surface varies considerably from near free stream to a throat Mach number of about 1.22.

Chima $^{(3)}$ provides an excellent and extensive review on the research into inlet buzz. However, that body of work does not provide much insight into the understanding and analysis of the unsteady data obtained from DES analyses ${ }^{(4)}$. That is because the process described from this analysis is fundamentally stochastic and not deterministic. There are however, in the body of literature, approximate statistical assessments of dynamic-distortion levels ${ }^{(5-8)}$. This involves the measurement of the steady state total pressures and the RMS of the time varying total pressures using some or all of the rake probes at the Aerodynamic Interface Plane (AIP) station downstream inlet. The assumption was made that the fluctuating total pressures are normally distributed and that mean and RMS of the total pressures do not vary with time. In other words, the process is statistically stable or stationary, and the model proposed was a stochastic stationary model. However, the phenomenon of dynamic distortion or any unsteady inlet process such as inlet buzz, is non-stationary. That is because there are both random and coherent unsteady structures within these inlet flows. What is needed is a stochastic non-stationary model.

Many series actually encountered in aerodynamics exhibit non-stationary behavior and in particular do not vary about a fixed mean. Such series nevertheless exhibit homogeneous behavior over time of a kind. In particular, although the general level about which fluctuations are occurring may be different at different times, the broad behavior of the series, when differences in level are accounted for, may be similar over time. This behavior may be modeled in terms of autocorrelation and/or auto regression methods. These techniques are used for the following reasons, namely: (1) to detect coherent unsteady structures within data that contains random variations and (2) to identify an appropriate time series (or any other series) model if the data contains coherent structures. Essentially autocorrelation is the cross correlation with itself. It is a mathematical tool for finding repeated patterns which have been buried under noise, or identifying the missing fundamental frequency in a signal implied by its harmonics.

Autoregressive methods have similar purposes and the best and earliest example would be the method of least squares. Thus, understanding non-stationary behaviors lies in the data analysis techniques used to evaluate these processes. The definitive text on time series analysis is by Box, E. P., Jenkins, G. M., and Reinsel, G. $\mathrm{C}^{(9)}$ and was published in 2008.

This study focuses on the aerodynamic mechanisms that initiate and sustain the inlet buzz phenomena as indicated by Detached Eddy Simululation (DES) analysis of the LMCO N+2 supersonic inlet. Comparisons between the DES analysis of the Lockheed Martin Corporation (LMCO) N+2 inlet and schlieren photographs taken during the test of the Gulfstream Aerospace Corporation (GAC) Large Scale Low Boom inlet tests in the NASA 8x6 ft. Supersonic Wind Tunnel (SWT) ${ }^{(10-11)}$ will also be made. 


\section{RESULTS AND DISCUSSION}

\section{Inlet Geometry and Computational Variables}

This study will focus on the Lockheed Martin Company (LMCO) N+2 Low-Boom Supersonic Inlet Configuration. The flow path of the LMCO N+2 inlet design is schematically shown in Figure (1). The inlet was designed for a free stream cruise Mach number of 1.70. The centerbody consists of an isentropic compression spike, a curved throat region, and a subsonic diffuser. The compression spike was designed to produce a variable-strength normal shock at the throat with a Mach number ahead of the shock of about 1.25 near the centerbody. The shock is weak at the centerbody to minimize shock/boundary-layer interaction and was stronger at the cowl lip. The forward centerbody of this inlet has a conical half angle, $\theta_{c}$ of 10.0 degrees, while the subsonic diffuser is very short with an $\mathrm{L} / \mathrm{D}_{\mathrm{AIP}}$ of 1.116 .

Figure (1) depicts the inlet flow surfaces provided by LMCO for this analysis. There was no information provided for the inlet definition downstream of the AIP station. Therefore, to complete the inlet grid, a constant area section was constructed with a length ratio $\mathrm{L} / \mathrm{D}_{\mathrm{AIP}}$ of 1.0 followed by a convergent-divergent nozzle to control the inlet mass flow. Figure (2) shows the inlet grid topology including the constant area section and the C-D nozzle. The computational grid contained $27.686 \times 10^{6}$ grid points with a total of 66 blocks. Each of the DES cases in the paper were run using the Wind-US V3.0 Reynolds-averaged Navier-Stokes code ${ }^{(12)}$.

Table (1) shows the flow variables that were held constant in this study. These were the free stream Mach Number, $M_{0}=1.70$, inlet angle of attack $\left(\alpha=0.0^{\circ}\right)$, inlet angle of yaw $(\beta=$ $\left.0.0^{\circ}\right)$, free stream total pressure $\mathrm{Pt}_{0}=2117.0 \mathrm{lbs} / \mathrm{ft}^{2}$, total temperature, $\left(\mathrm{T}_{0}=517.0{ }^{\circ} \mathrm{R}\right)$, and nominal free stream Reynolds number, $\left(\mathrm{Re}=3.9 \times 10^{6} / \mathrm{ft}\right)$. The response variables in this study are shown in Table (2). These were the average Mach number (MAIP) and total pressure recovery (PFAIP) calculated at the AIP station. The important time variables used in this study are shown in Table (3), and includes the DES computational time step, i.e. $1.0 \times 10^{-6}$ seconds and sampling rate of one sample every $1.0 \times 10^{-4}$ seconds. The CFD sampling rate was chosen so that it was the same as the standard experimental rate of 10,000 samples/sec used in dynamic distortion studies. Assuming a fan speed of 4300 RPM, the sampling span becomes $1.395 \times 10^{-2}$ seconds/rev. Since it is desirable to sample data over not less than $1.0 \mathrm{rev}$. of the fan, the total number of CFD samples was therefore set at 141 (40 time increments) in this study. This covered just over one revolution of the engine fan.

\section{Flow Physics of a Choked Nozzle}

A key to understanding the feedback mechanism of inlet buzz is the flow physics of the choked nozzle. A choked nozzle is essentially a device that passes a constant amount of corrected airflow, determined only by the nozzle minimum area. The expression for inlet corrected airflow in slugs/sec is given by:

$$
\frac{w \sqrt{\Theta}}{\delta}=\frac{P_{r e f}}{\sqrt{T_{\text {ref }}}} \sqrt{\frac{\gamma}{R}} M\left(1.0+\frac{(\gamma-1.0)}{2} M^{2}\right)^{-\frac{(\gamma+1.0)}{2(\gamma-1.0)}} A
$$


Where $w$ is the weight flow, $\sqrt{\Theta}$ is the square root of the total temperature ratio $\left(T_{0} / T_{r e f}\right), \delta$ is the total pressure ratio $\left(P_{0} / P_{\text {ref }}\right), P_{\text {ref }}$ is the standard sea level total pressure of $2117.0 \mathrm{lbs} / \mathrm{ft}^{2}, T_{\text {ref }}$ sea level total temperature of $517.0^{\circ} \mathrm{R}, \gamma$ is the specific heat ratio, $R$ is the gas constant, $M$ is the average Mach number at the survey station, and A is the survey station area. Thus, for a supersonic inlet with a choked nozzle to control the corrected airflow, the Mach number $M$ at the throat station becomes 1.0, and the inlet corrected airflow $\frac{w \sqrt{\theta}}{\delta}$ becomes only a function of the nozzle throat area $A$. This property of a choked nozzle is very important to understanding inlet buzz. Once the nozzle has been restricted to induce inlet buzz, the choked nozzle always wants to maintain a constant inlet corrected airflow during the buzz cycle. The inlet corrected airflow is important because supersonic inlets are designed to provide a specific corrected airflow to the engine at a given flight condition, and the CFD analysis of the inlet must converge to that specific amount. It therefore represents an important mass flow test for convergence of the CFD analysis. The inclusion of the choked nozzle in the CFD analysis is very important because it is the only viable downstream boundary condition for the DES analysis. All other boundary condition will reflect the turbulent eddies back into the flow field domain causing sever numerical problems.

\section{Flow Physics of Inlet Buzz}

The details of the buzz onset and development of the subsequent flow field in the LMCO $\mathrm{N}+2$ inlet as the back pressure is increased can be characterized in three phases which are shown in Figure (3) as marked out on the LMCO N+2 inlet Cane curve characteristics. As the back pressure increases capture mass flow ratio on the Cane curve decreases. Firstly, in Phase (1) at low spillage (critical operating condition), a high frequency low amplitude oscillation of the normal shock exists. The inlet Mach number contours for Phase (1) inlet operation are shown in Figures (4) through (6). This is succeeded by Phase (2) in Figure (3), as the back pressure is further increased (subcritical operation), to a high frequency higher amplitude oscillation which is stable and dominated by the development of separation bubbles at the normal SWBL interaction on the isentropic spike. The inlet Mach number contours in Phase (2) are in Figures (7) through (9). Further increasing the back pressure then leads to another phase, commonly called buzz, and involves a very high amplitude oscillation of the entire shock system, Phase (3) in Figure (3). In the LMCO N+2 inlet buzz was initiated at an inlet capture mass flow ratio $\left(\mathrm{m} / \mathrm{m}_{0}\right)$ of about 0.55 . The initiation of this phase is dominated by a completely detached normal shock wave boundary layer separation, and this is the triggering instability for the buzz cycle in this inlet. The Phase (3) inlet buzz is illustrated in Figures (10) through (12). Figure (10) presents Mach number contours in the inlet prior to and during an inlet buzz event. The time at each point in the buzz sequence is indicated on the figures. Figure (11) shows Mach conditions at the AIP for each of the same series of time steps while Figure (12) presents Mach number contours on an axial cross-section of the inlet, with increased magnification to show detail in the inlet to approximately the AIP station.

Figures (13) and (14) present the instantaneous area-averaged Mach number and total pressure recovery, respectively at the AIP that corresponds to the flow field contours in Figures (10) through (12). The time scale on the abscissa of these plots may be used to assess the AIP 
conditions at the relative time $(\Delta \mathrm{t})$ in seconds indicated in the captions in Figures (10) through (12). At $\Delta \mathrm{t}=0.0$ seconds, Figure (10a), the inlet is operating in a stable fashion at critical inlet operating conditions. The unsteady terminal shock wave is located at the cowl lip, which is the normal operating condition for the inlet. Note that the convergent-divergent (C-D) nozzle area is large, allowing the operating point corrected flow rate to be passed. At a time of $\Delta \mathrm{t}=0.5 \times 10^{-3}$ seconds, Figure (10b), the C-D nozzle throat area has been significantly reduced. This reduction in nozzle area will not allow the flow being captured by the inlet at the critical operating condition to be passed, and, therefore will trigger the onset of buzz. Already, the Mach number at the AIP is significantly reduced. Figure (11b), and Figures (17) and (18) show that the moment the nozzle area is reduced, the Mach number falls, and the local AIP total pressure recovery increases. This decrease in nozzle area requires that the corrected flow that can be passed must decreased. The reason for this decrease is that a choked nozzle is essentially a device that passes a constant amount of corrected airflow, determined by the nozzle minimum area. The instantaneous reduction in corrected airflow at the exit nozzle requires that the inlet capture less flow. Therefore, the Mach number of the local flow near the exit of the diffuser immediately begins to decrease. A wave of low energy (low pressure) flow moves upstream in the inlet, as may be seen at $\Delta \mathrm{t}=1.0 \times 10^{-3}$ seconds, Figure (10c). At this time in the buzz sequence, the Mach number at the AIP has begun to decrease and the total pressure has begun to increase as may be seen in Figures (13) and (14). In fact, Figure (14) indicates that total pressure recovery increases to above 1.0. The reason for this effect is that the total temperature does not remain constant in an unsteady process such at buzz. Hence, the local total temperature is changing under these dynamic flow conditions. At $\Delta \mathrm{t}=1.5 \times 10^{-3}$ seconds, Figure (10d), the terminal shock wave has moved significantly upstream of the cowl lip, allowing additional flow to spill around the cowl, and thereby reducing the captured corrected airflow, as the nozzle demands. The strong external shock wave interacts with the boundary layer on the centerbody, and a lambda-type system of smaller oblique shocks forms at the base of the normal shock. Instability of the flow around this shock boundary layer interaction is evident in the local flow eddies near the spike surface. At time $\Delta \mathrm{t}=2.0 \times 10^{-3}$ seconds, the terminal shock has moved further upstream, and the local flow on the centerbody surface upstream of the cowl lip is massively unsteady. Figures (17) and (18) indicate that Mach number at the AIP continues to decrease, while recovery has peaked and started to decrease again. By time $\Delta \mathrm{t}=2.5 \times 10^{-3}$ seconds, Figure (10e), the terminal shock has moved all the way upstream of the spike tip. Large regions of separation and unsteady flow persist on the spike, and are evident now near the tip. At $\Delta \mathrm{t}=3.0 \times 10^{-3}$ seconds, Figure (10f), the terminal shock is at its most forward position, and large quantities of flow continue to spill around the cowl lip. Fewer flow eddies are visible near the centerbody because the normal shock is no longer interacting with the boundary layer on the spike. The Mach number at the AIP has almost reached a minimum. Because of over spillage, the fixed nozzle area can pass more than the significantly decreased flow that is being captured by the inlet. Therefore, the flow field must compensate in the other direction by spilling less flow, and the terminal shock begins to move downstream again. This can be seen at time $\Delta \mathrm{t}=3.5 \times 10^{-3}$ seconds, Figure $(10 \mathrm{~g})$, the local Mach number of the flow around the inside of the cowl lip has increased locally. From time $\Delta \mathrm{t}=3.5 \times 10^{-3}$ to $4.0 \times 10^{-3}$ seconds, Figures $(10 \mathrm{~g})$ and $(10 \mathrm{~h})$, the local Mach number of the flow entering the inlet is increasing, and the Mach number at the AIP increases dramatically, as the nozzle is now able to pass more corrected flow than is being supplied. At time $\Delta t=4.0 \times 10^{-3}$ seconds, Figure (10h), the terminal shock has moved further downstream, and begins to interact 
with the boundary layer on the centerbody. A lambda-shock begins to form at the base of the terminal shock. The lambda shock becomes larger at time $\Delta t=4.5 \times 10^{-3}$ seconds, Figure (10i), and the Mach number of the flow entering the inlet has increased, thus increasing the captured corrected airflow. Instabilities in the flow near the surface of the centerbody begin to become evident again. At time $\Delta \mathrm{t}=5.0 \times 10^{-3}$ seconds, Figure $(10 \mathrm{j})$, the lambda formation is large, and the Mach number of the flow being captured has increased further. Meanwhile, the Mach number of the flow at the AIP is on the decline, and the corrected airflow that the nozzle can pass does not match the corrected flow that is now being captured. Therefore, the inlet now needs to spill additional airflow. At $\Delta \mathrm{t}=5.5 \times 10^{-3}$ seconds, Figure (10k), the normal shock has begun to move upstream again, with separation and unsteady flow eddies being formed near the centerbody. This flow condition Figure $(11 \mathrm{k})$, appears to be similar to that shown at time $\Delta \mathrm{t}=1.5 \times 10^{-3}$ in Figure (11d). As before, the shock continues to move upstream from times $\Delta \mathrm{t}=5.5 \times 10^{-3}$ to $\Delta \mathrm{t}=7.0 \times 10^{-3}$ seconds, Figures $(11 \mathrm{k})$ to Figure $(11 \mathrm{n})$, in a fashion similar to times $\Delta \mathrm{t}=1.5 \times 10^{-3}$ to $\Delta \mathrm{t}=3.0 \times 10^{-3}$ seconds, Figures (11d) to (11f). As is evident in Figures (17) and (18), the buzz cycle begins to repeat at approximately time $\Delta t=7.5 \times 10^{-3}$ seconds, Figure $((10 \mathrm{o})$, As before, the terminal shock attempts to adjust its location to provide the proper amount of corrected flow that the nozzle will pass, but unstable flow conditions generated in the region of the shock wave boundary layer interaction prevent the inlet from establishing a steady-state condition in which the terminal shock is located upstream on the centerbody spike. The shock wave continues upstream until the inlet captures insufficient flow to match the nozzle, and the shock system moves downstream yet again.

\section{Comparison with Experimental Data}

As part of the NASA High Speed Project, two supersonic inlet concepts were evaluated for the purpose of overcoming the efficiency, environmental, and performance barriers to practical supersonic flight. The first of these inlet concepts was designed by the Gulfstream Aerospace Corporation (GAC), and experimentally tested in the 8x6 ft. Supersonic Wind Tunnel at NASA Glenn Research Center ${ }^{(9-10)}$. This Large Scale Low Boom (LSLB) inlet design used an axisymmetric, relaxed isentropic compression centerbody design to decelerate the flow into nonuniform terminal shock, very similar in geometry to the LMCO N+2 design. Although the Gulfstream inlet concept had a vastly different design philosophy from the LMCO N+2 design concept considered in this paper, the two inlets were sufficiently similar in geometry that experimental schlieren data from the 8x6 SWT test of the Gulfstream inlet can be used to subjectively evaluate DES analysis of the LMCO N+2 design during the buzz cycle. The results of this comparison between the DES analyses of the LMCO N+2 inlet buzz cycle and schlieren photographs of the Gulfstream concept under buzz conditions is presented in Figures (15) through (18). Figures (15) and (16) show the comparison between the DES analysis and schlieren photographs of the flow field when the normal shock is advancing upstream, while Figures (17) and (18) show the same comparisons when the normal shock is receding downstream. The four comparisons in these figures show similarities in turbulent flow field and shock wave structure at vastly different stages of the buzz cycle.

\section{SUMMARY OF RESULTS}

All supersonic inlets with external compression, having a good level of performance at the critical operating point, exhibit a marked instability of the flow in some subcritical operation 
below a critical value of the capture mass flow ratio. This takes the form of severe oscillations of the shock system, commonly known as "buzz". The intrinsic interest in the inlet buzz phenomenon is centered on two basics questions, (1) what is the triggering instability that initiates the inlet buzz cycle?, and (2) what is the aerodynamic mechanism that sustains inlet buzz? The underlying purpose of this study is to indicate how DES type of inlet analysis will alter how we envision unsteady inlet aerodynamics. Thus this study covered the physical explanation underlying inlet buzz as indicated by DES analysis. It is the normal shock wave boundary layer separation along the spike surface which reduces the capture mass flow that is the controlling mechanism which determines the onset of inlet buzz, and it is the aerodynamic characteristics of a choked nozzle that provide the feedback mechanism that sustains the buzz cycle by maintaining a constant mean corrected inlet weight flow. Comparisons between the DES analysis of the LMCO N+2 inlet and Schlieren photographs taken in test of the Gulfstream (LSLB) inlet in the NASA $8 \times 6 \mathrm{ft}$. SWT show a strong similarity both in flow field and shock wave structure during the buzz cycle. This demonstrates the value of DES analysis for the design and understanding of supersonic inlets. 


\section{REFERENCES}

1. Oswatitch, K "Der Drukruckgewinn bei Geschossen mit Ruckstorsanttrib bei hohen Uberschallgeschwindigkeiten", Gottingen paper. English translation in NASA TN 1140, 1944.

2. Ferri, A and Nucci, L. M. "The origin of aerodynamic instability of supersonic inlets at subcritical conditions”, NACA RM L50 K30. 1951.

3. Chima, R. “Analysis of Buzz in a Supersonic Inlet”, NASA/TM-2012-217612, 2012.

4. Spalart, P. "Detached-Eddy Simulation," Annual Review of Fluid Mechanics, Vol. 41: 181-202, January 2009.

5. Sedlock, D. "Improved statistical analysis method for prediction of maximum inlet distortion", AIAA 84-1274, 1984.

6. Sedlock, D. "Statistical analysis method for prediction of peak inlet flow distortion", Journal of Propulsion and Power, 1 (5), 354, 1985.

7. Stevens, C. "Evaluation of a statistical method for prediction of maximum inlet distortion using F15and F18 data", AIAA 80-1109, 1980.

8. Borg, R. “A synthesis method for estimating maximum inlet distortion” Paper 19, AGARD CP 301, 1981.

9. Box, E. P., Jenkins, G. M., and Reinsel, G. C.: "Time Series Analysis”, John Wiley \& Sons, 2008.

10. Hirt, S. M., Chima, R.V., Vyas, M. A., Wayman, T. R., Conners, T. R., and Reger, R. W., "Experimental Investigation of a Large-Scale Low-Boom Inlet Concept", AIAA 20113796, 29th AIAA Applied Aerodynamics Conference, 27 - 30 June 2011, Honolulu, Hawaii, 2011.

11. Vyas, M. A, Hirt, S. M., Chima, R, V., Davis, D. O., and Wayman, T. R., "Experimental Investigation of Vortex Generators on a Low-Boom Supersonic Inlet”, AIAA 2011-3798, 29th AIAA Applied Aerodynamics Conference, 27 - 30 June 2011, Honolulu, Hawaii, 2011.

12. Towne, C.E. “Wind-Us User’s Guide, Version 2.0, NASA TM-2009-215804, 2009. 


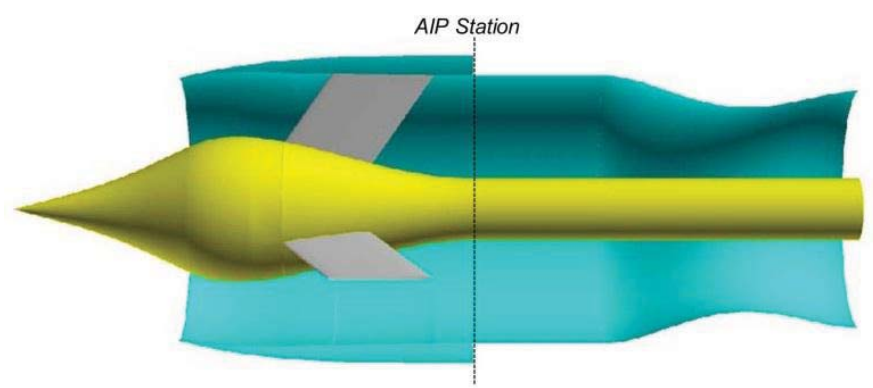

Figure (1): Schematic diagram of LMCO N+2 inlet design.

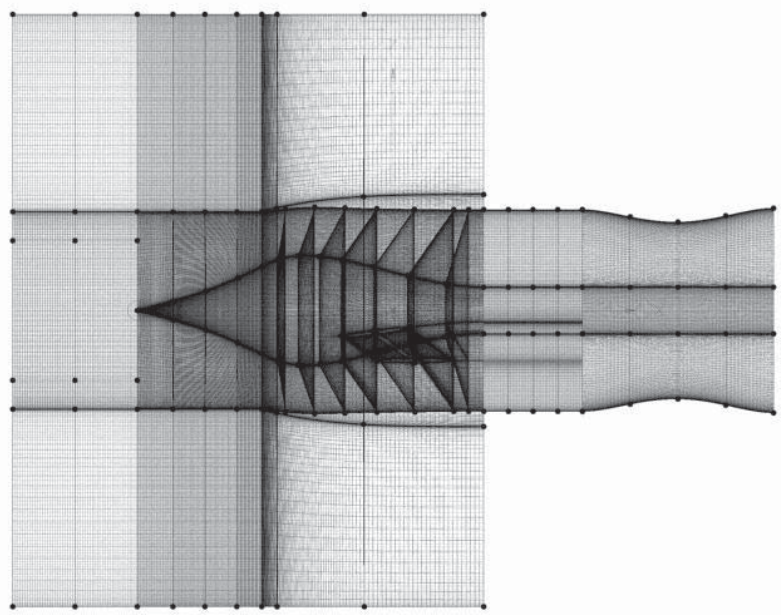

Figure (2): Computational grid for LMCO N+2 inlet design, Grid $=27.686 \times 10^{6}$, Blocks $=66$.

\begin{tabular}{|c|c|}
\hline Factor Variable & Range \\
\hline Free Stream Mach Number, $M_{0}$ & 1.7 \\
\hline Inlet Angle of Attack, $\alpha$ & $0.0^{\circ}$ \\
\hline Inlet Angle of Yaw, $\beta$ & $0.0^{\circ}$ \\
\hline Free Stream Total Pressure $\left(\mathrm{lbs} / \mathrm{ft}^{2}\right), P_{\circ}$ & 2117.0 \\
\hline Free Stream Total Temperature $\left({ }^{\circ} \mathrm{R}\right), \mathrm{T}_{\circ}$ & 517.0 \\
\hline Nominal Free Stream Reynolds Number $($ per $\mathrm{ft}),. \mathrm{Re}$ & $3.9 \times 10^{6}$ \\
\hline
\end{tabular}

Table (1): Flow variables held constant.

\begin{tabular}{|c|c|}
\hline Response Variable & Symbol \\
\hline AIP Area Average Mach Number & MFAIP \\
\hline AIP Critical Total Pressure Recovery & PFAIP \\
\hline
\end{tabular}

Table (2): ARP1420 response variables.

\begin{tabular}{|c|c|}
\hline Time Variable & Value \\
\hline Computational Time Step, Sec. & $1.0 \times 10^{-6}$ \\
\hline CFD Data Sampling Rate, Sec & $1.0 \times 10^{-4}$ \\
\hline Per/Rev Time Span (4300 RPM), Sec. & $1.395 \times 10^{-2}$ \\
\hline CFD Data Per/Rev Sampling Time Span, Sec(1) & $1.4 \times 10^{-2}$ \\
\hline Total Number of Data Samples in 1 rev. & 141 \\
\hline
\end{tabular}

Table (3): Important DES flow variables.

$$
\text { - - - LMCO Design Goal }
$$

O LMCO Low Boom N+2 Inlet

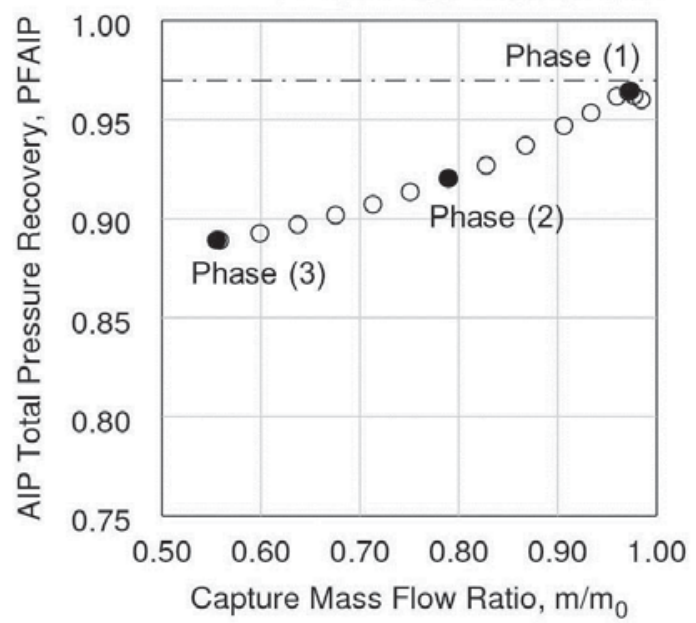

Figure (3): Typical phases of inlet unsteadiness leading to inlet buzz as indicated on the Cane curve.

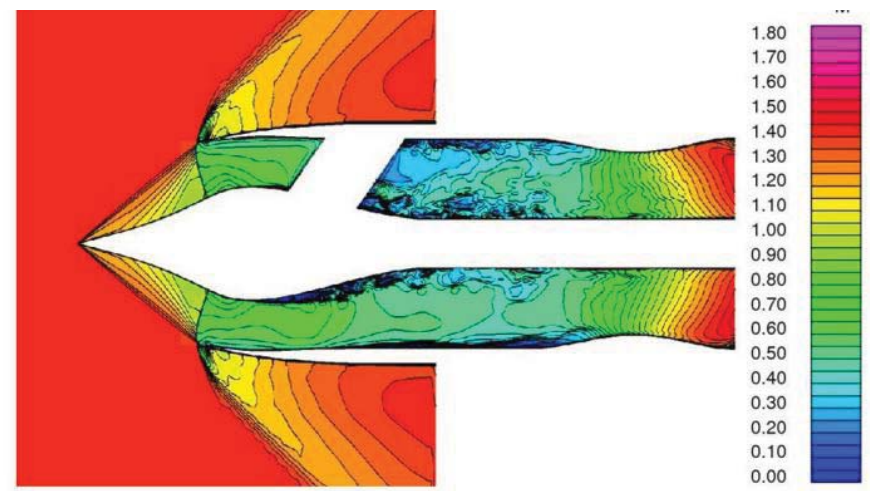

Figure (4): Typical DES analysis phase (1) inlet operations, streamwise Mach number contours.

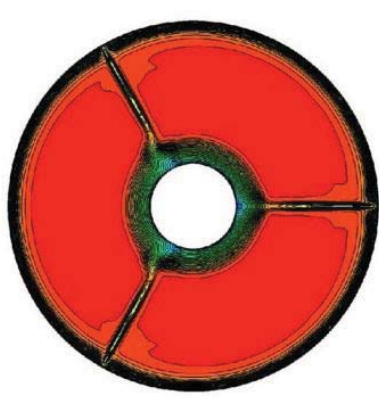

(a) 3D Steady RNS analysis (b) 3D Unsteady DES analysis

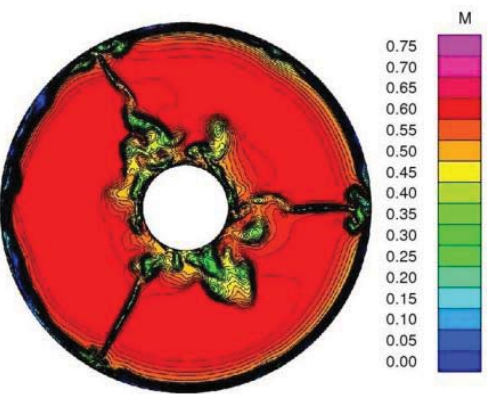

Figure (5): Typical analysis phase (1) inlet operations, AIP Mach number contours. 


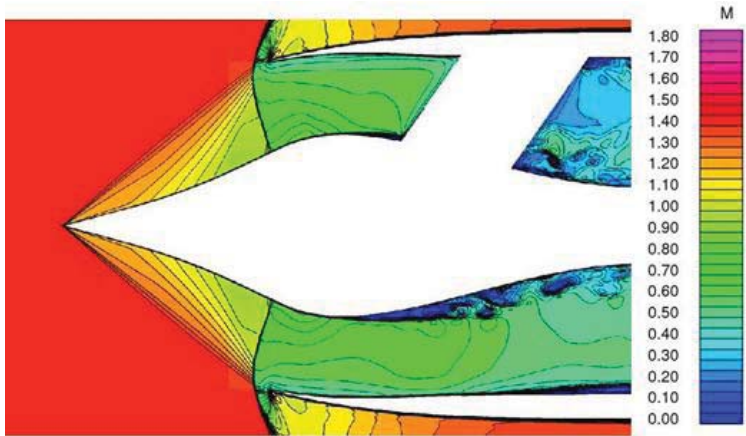

Figure (6): Typical DES analysis phase (1) inlet operations, streamwise Mach number contours.

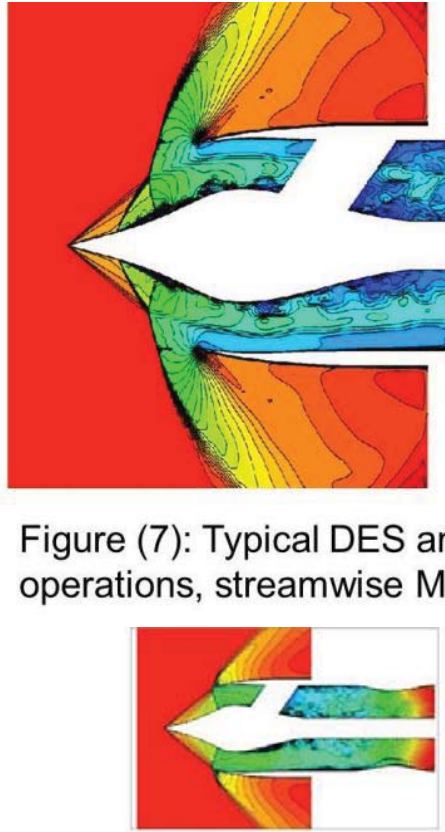

(a) $\Delta \mathrm{t}=0.0 \mathrm{sec}$.

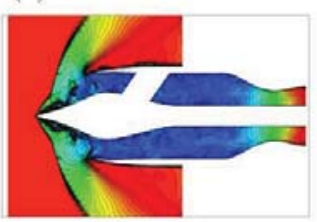

(d) $\Delta t=2.0 \times 10^{-3} \mathrm{sec}$.

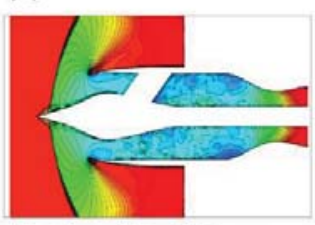

(h) $\Delta t=4.0 \times 10^{-3} \mathrm{sec}$.

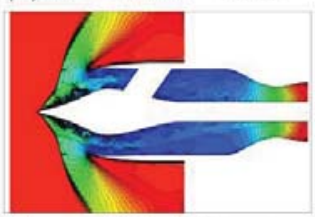

(I) $\Delta \mathrm{t}=6.0 \times 10^{-3} \mathrm{sec}$.

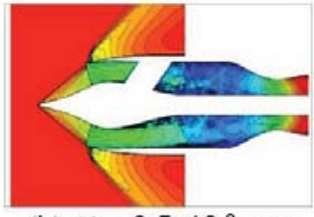

(b) $\Delta t=0.5 \times 10^{-3} \mathrm{sec}$.

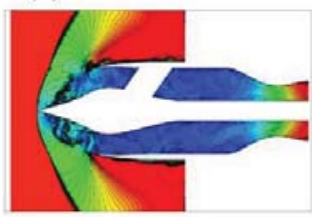

(e) $\Delta t=2.5 \times 10^{-3} \mathrm{sec}$.

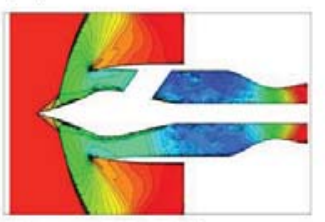

(i) $\Delta \mathrm{t}=4.5 \times 10^{-3} \mathrm{sec}$.

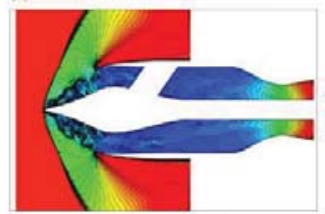

(m) $\Delta \mathrm{t}=6.5 \times 10^{-3} \mathrm{sec}$.

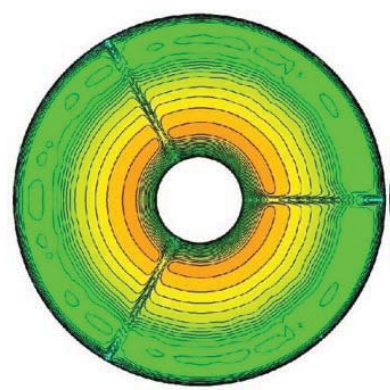

(a) 3D Steady RNS analysis

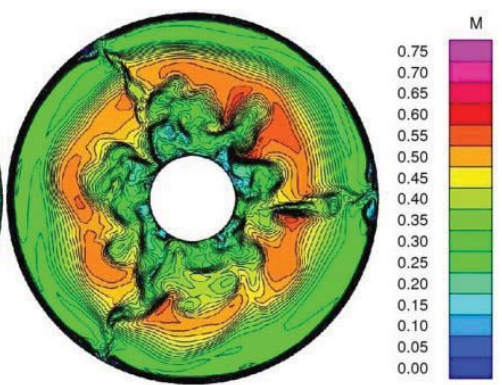

(b) 3D Unsteady DES analysis

Figure (8): Typical analysis phase (2) inlet operations, AIP Mach number contours.
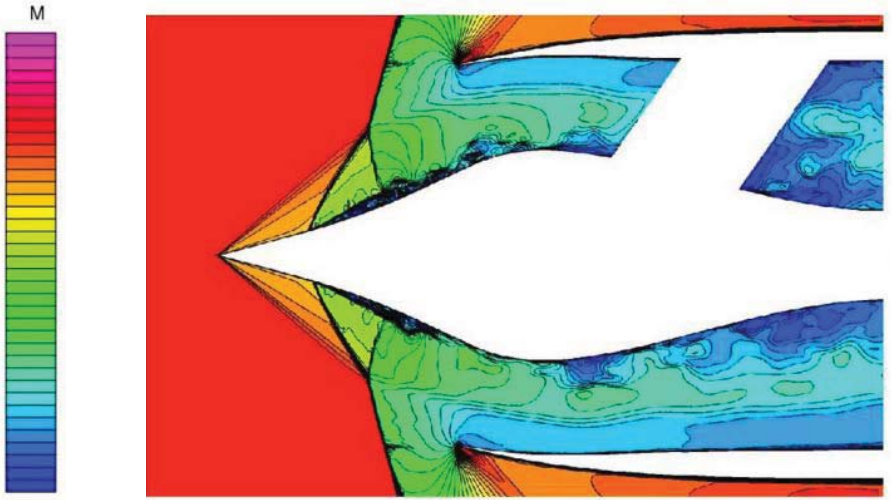

$M$

Figure (9): Typical DES analysis phase (2) inlet operations, streamwise Mach number contours.

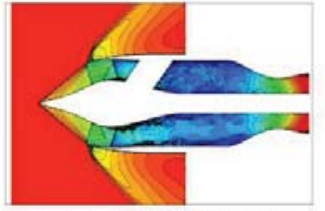

(c) $\Delta t=1.0 \times 10^{-3} \mathrm{sec}$.

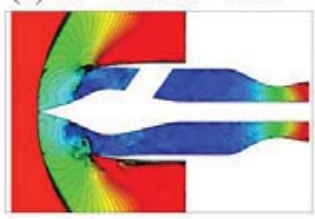

(f) $\Delta t=3.0 \times 10^{-3} \mathrm{sec}$.

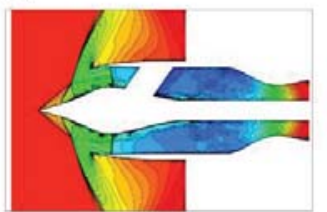

(j) $\Delta t=5.0 \times 10^{-3} \mathrm{sec}$.

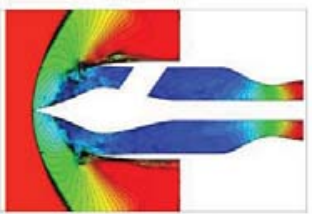

(n) $\Delta \mathrm{t}=7.0 \times 10^{-3} \mathrm{sec}$.

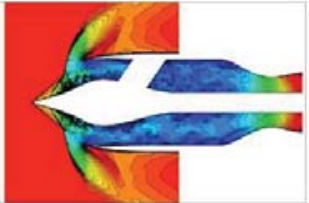

(d) $\Delta t=1.5 \times 10^{-3} \mathrm{sec}$.

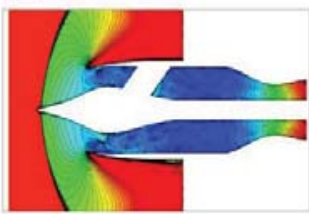

(g) $\Delta \mathrm{t}=3.5 \times 10^{-3} \mathrm{sec}$.

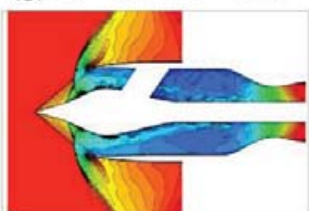

(k) $\Delta \mathrm{t}=5.5 \times 10^{-3} \mathrm{sec}$.

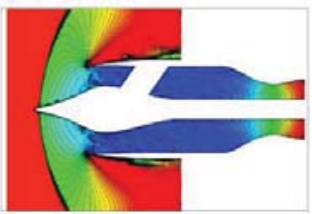

(o) $\Delta \mathrm{t}=7.5 \times 10^{-3} \mathrm{sec}$.

Figure (10): Typical phase (3) inlet buzz streamwise Mach number contours.

American Institute of Aeronautics and Astronautics 


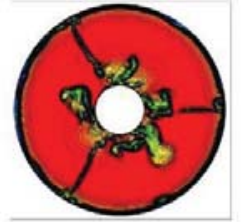

(a) $\Delta \mathrm{t}=0.0 \mathrm{sec}$.

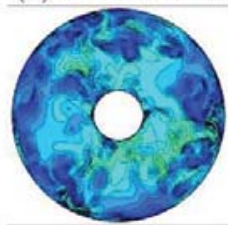

(d) $\Delta t=2.0 \times 10^{-3} \mathrm{sec}$.

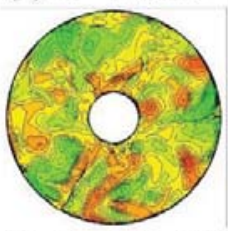

(h) $\Delta \mathrm{t}=4.0 \times 10^{-3} \mathrm{sec}$.

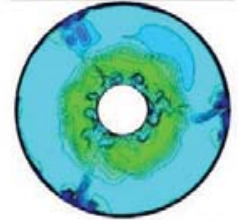

(I) $\Delta \mathrm{t}=6.0 \times 10^{-3} \mathrm{sec}$.

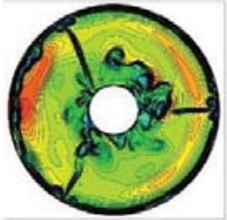

(b) $\Delta \mathrm{t}=0.5 \times 10^{-3} \mathrm{sec}$.

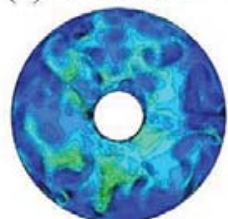

(e) $\Delta t=2.5 \times 10^{-3} \mathrm{sec}$.

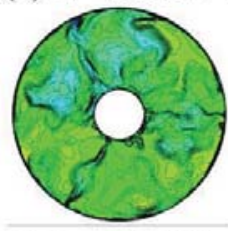

(i) $\Delta t=4.5 \times 10^{-3} \mathrm{sec}$.

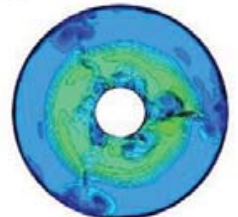

(m) $\Delta t=6.5 \times 10^{-3} \mathrm{sec}$.

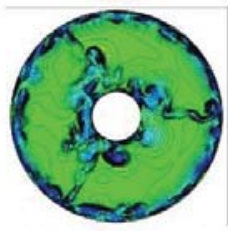

(c) $\Delta t=1.0 \times 10^{-3} \mathrm{sec}$.

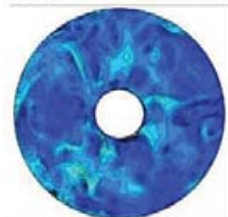

(f) $\Delta t=3.0 \times 10^{-3} \mathrm{sec}$.

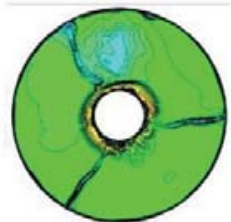

(j) $\Delta t=5.0 \times 10^{-3} \mathrm{sec}$.

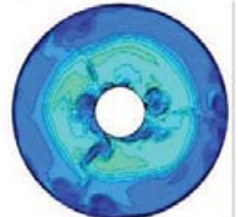

(n) $\Delta t=7.0 \times 10^{-3} \mathrm{sec}$.

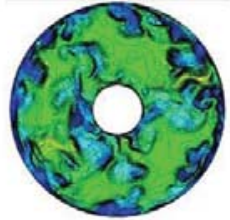

(d) $\Delta \mathrm{t}=1.5 \times 10^{-3} \mathrm{sec}$.

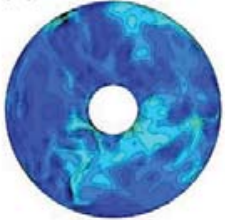

(g) $\Delta \mathrm{t}=3.5 \times 10^{-3} \mathrm{sec}$.

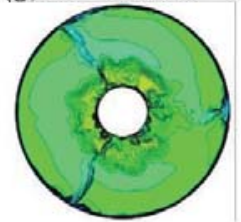

(k) $\Delta t=5.5 \times 10^{-3} \mathrm{sec}$.

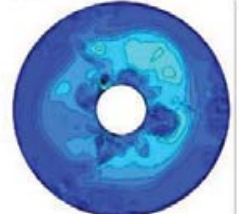

(o) $\Delta t=7.5 \times 10^{-3} \mathrm{sec}$.

Figure (11): Typical phase (3) inlet buzz AIP Mach number contours.

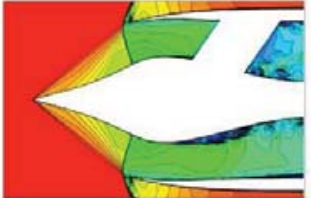

(a) $\Delta \mathrm{t}=0.0 \mathrm{sec}$.

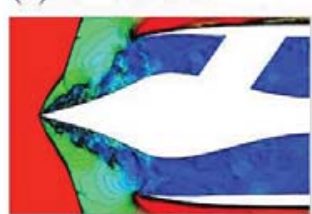

(d) $\Delta \mathrm{t}=2.0 \times 10^{-3} \mathrm{sec}$.

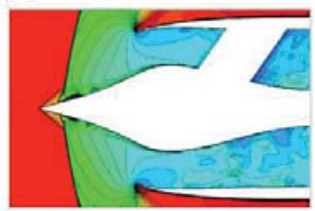

(h) $\Delta t=4.0 \times 10^{-3} \mathrm{sec}$.

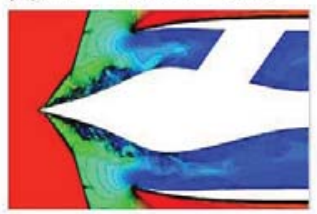

(I) $\Delta t=6.0 \times 10^{-3} \mathrm{sec}$.

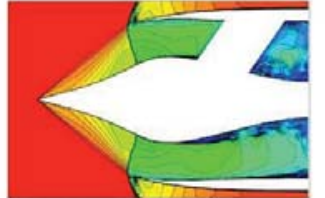

(b) $\Delta t=0.5 \times 10^{-3} \mathrm{sec}$.

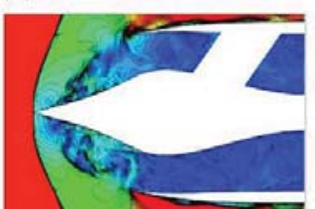

(e) $\Delta t=2.5 \times 10^{-3} \mathrm{sec}$.

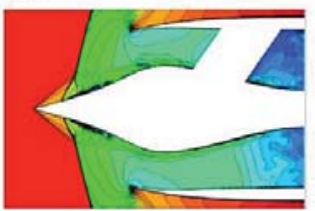

(i) $\Delta t=4.5 \times 10^{-3} \mathrm{sec}$.

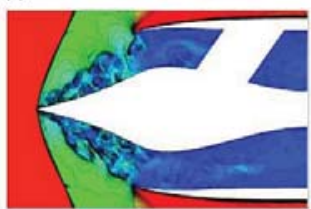

(m) $\Delta t=6.5 \times 10^{-3} \mathrm{sec}$.

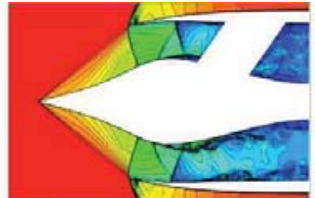

(c) $\Delta t=1.0 \times 10^{-3} \mathrm{sec}$.

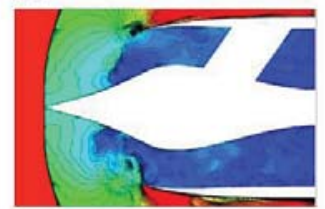

(f) $\Delta t=3.0 \times 10^{-3} \mathrm{sec}$.

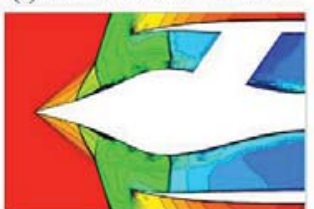

(j) $\Delta t=5.0 \times 10^{-3} \mathrm{sec}$.

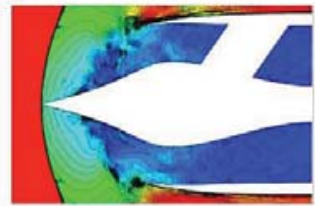

(n) $\Delta t=7.0 \times 10^{-3} \mathrm{sec}$.

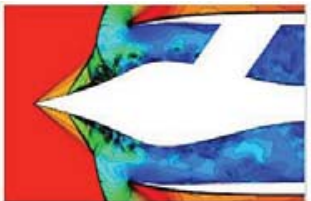

(d) $\Delta t=1.5 \times 10^{-3} \mathrm{sec}$.

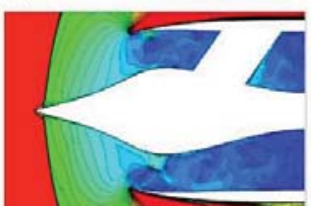

(g) $\Delta t=3.5 \times 10^{-3} \mathrm{sec}$.

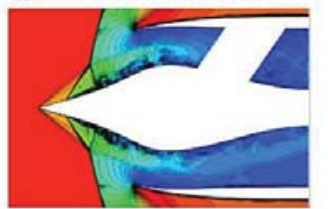

(k) $\Delta t=5.5 \times 10^{-3} \mathrm{sec}$.

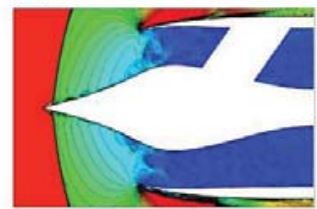

(o) $\Delta t=7.5 \times 10^{-3} \mathrm{sec}$.

Figure (12): Typical phase (3) inlet buzz streamwise Mach number contours.

American Institute of Aeronautics and Astronautics 

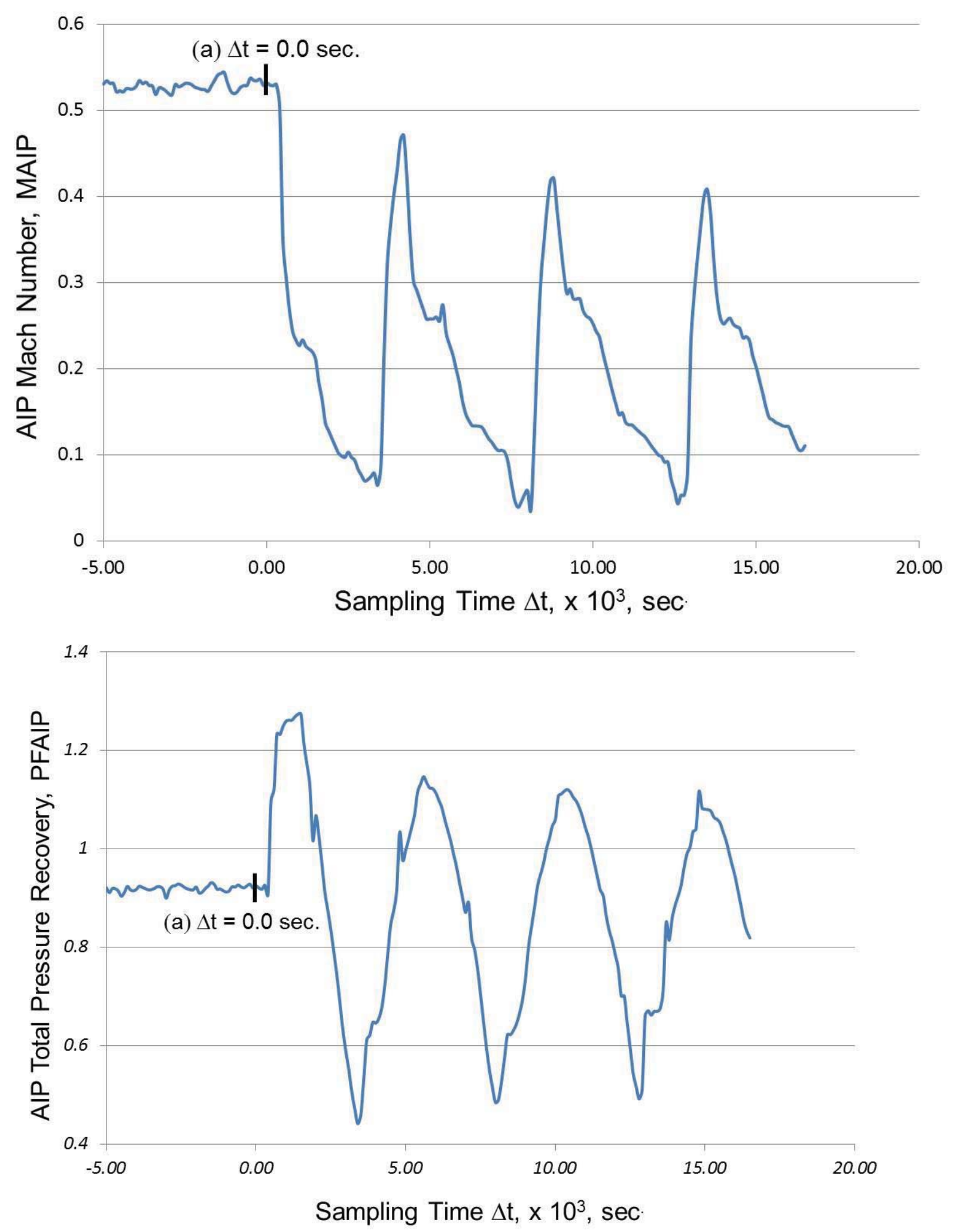

Figure (14): Instantaneous area averaged AIP Total Pressure Recovery, PFAIP.

American Institute of Aeronautics and Astronautics 


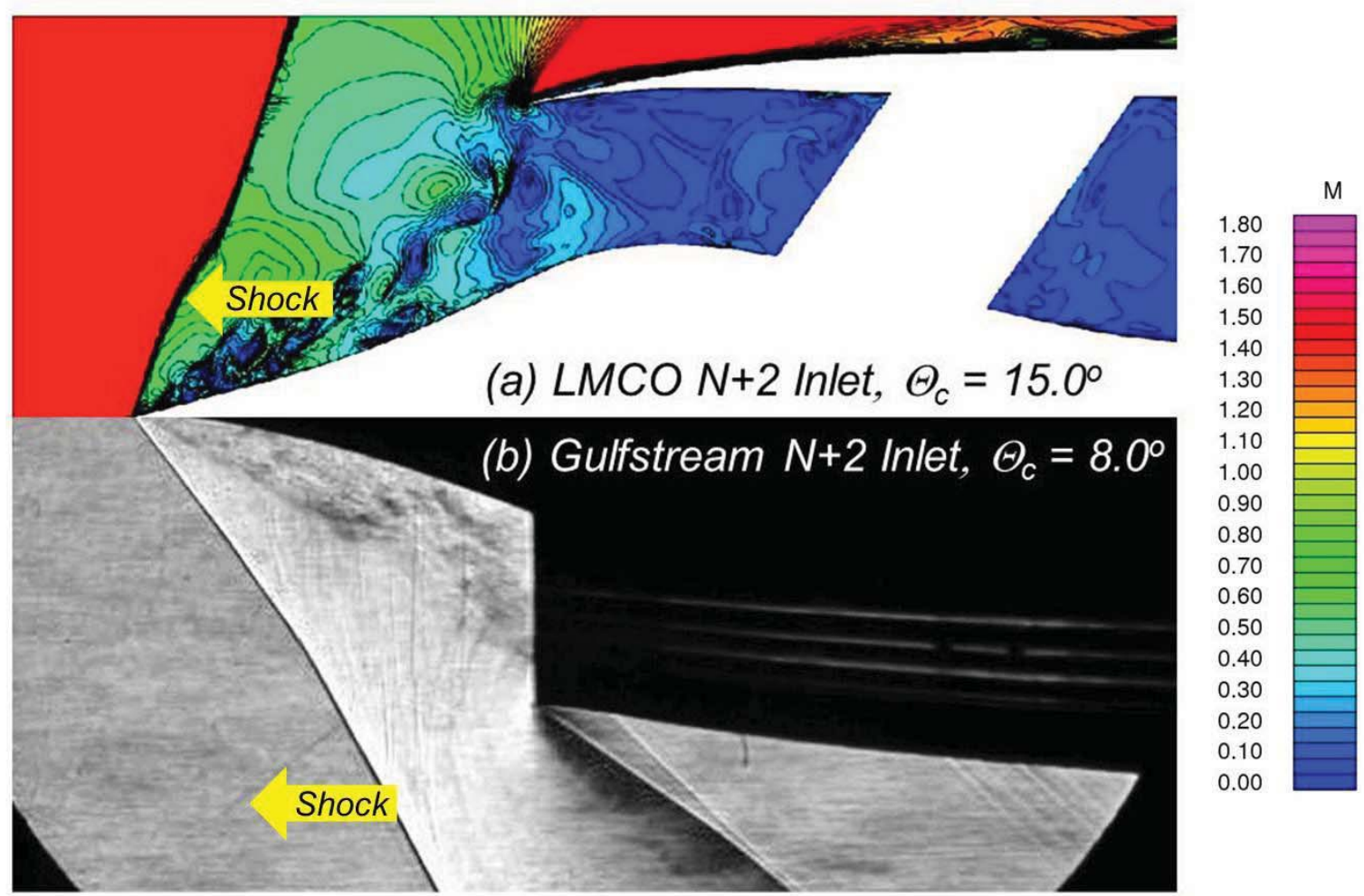

Figure (15): Comparison of CFD analysis and Schlieren photograph during buzz cycle, $\Delta \mathrm{t}=2.2 \times 10^{-3} \mathrm{sec}$.

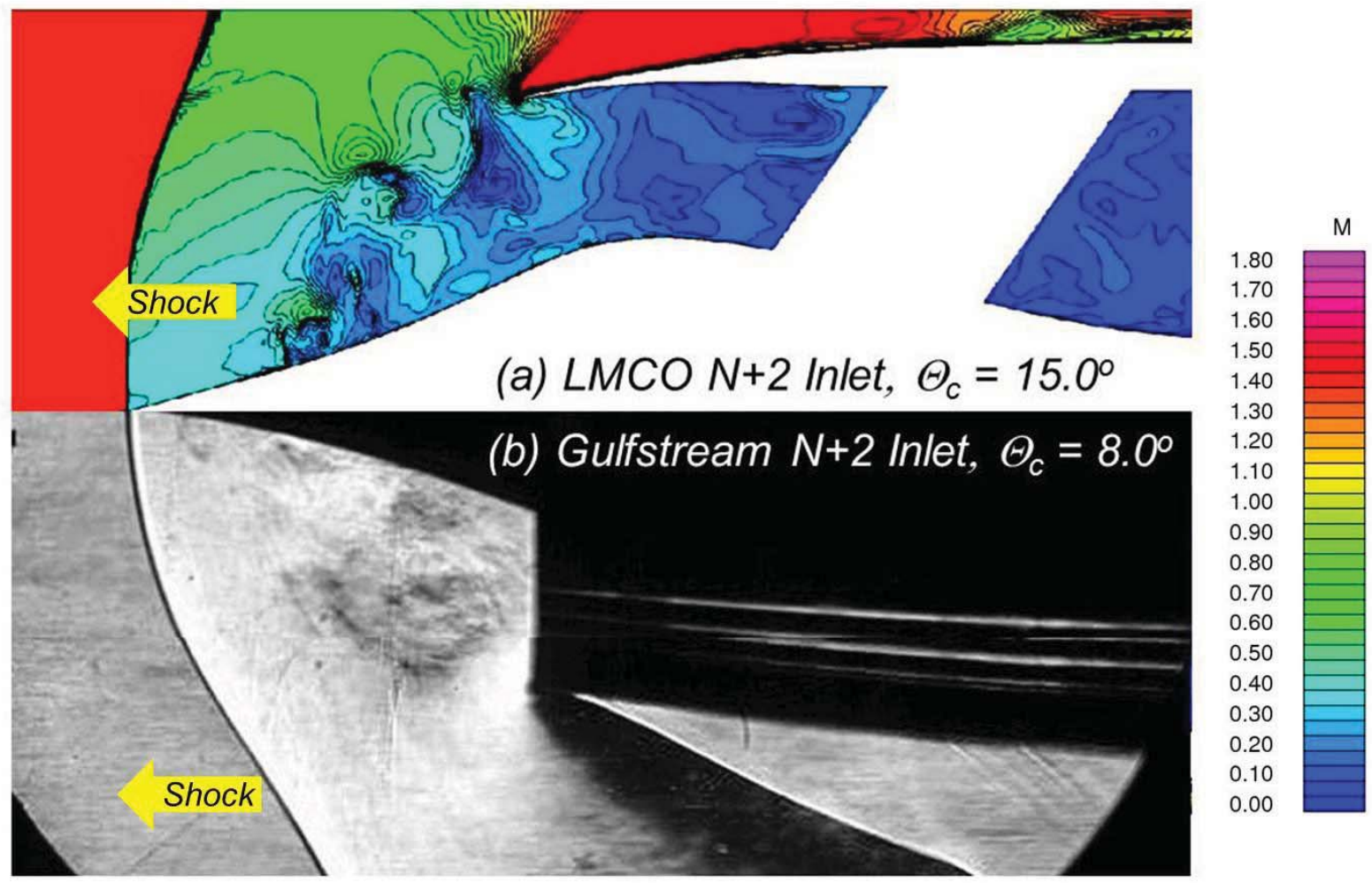

Figure (16): Comparison of CFD analysis and Schlieren photograph during buzz cycle, $\Delta t=3.0 \times 10^{-3} \mathrm{sec}$. 

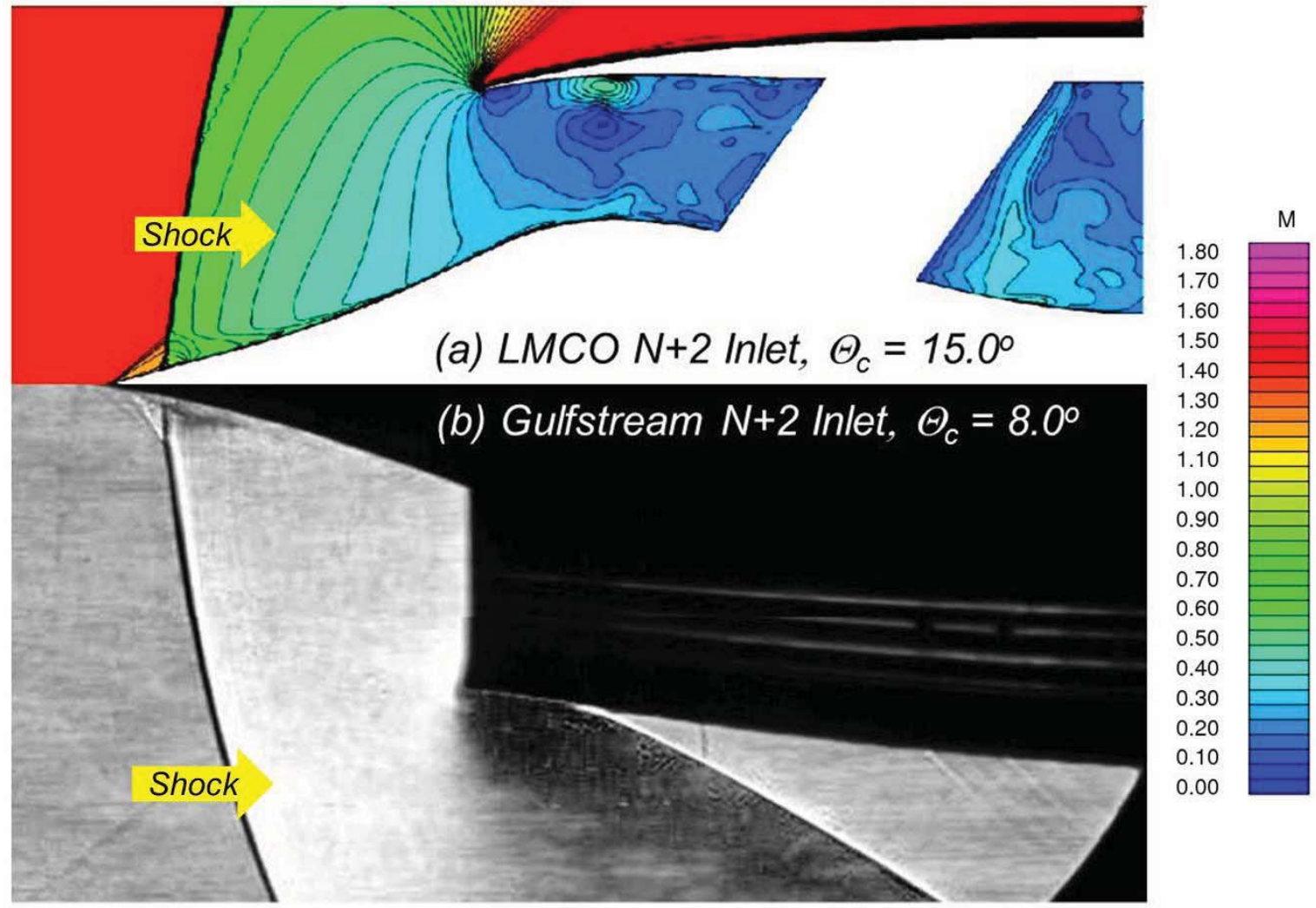

Figure (17): Comparison of CFD analysis and Schlieren photograph during buzz cycle, $\Delta t=3.6 \times 10^{-3} \mathrm{sec}$.

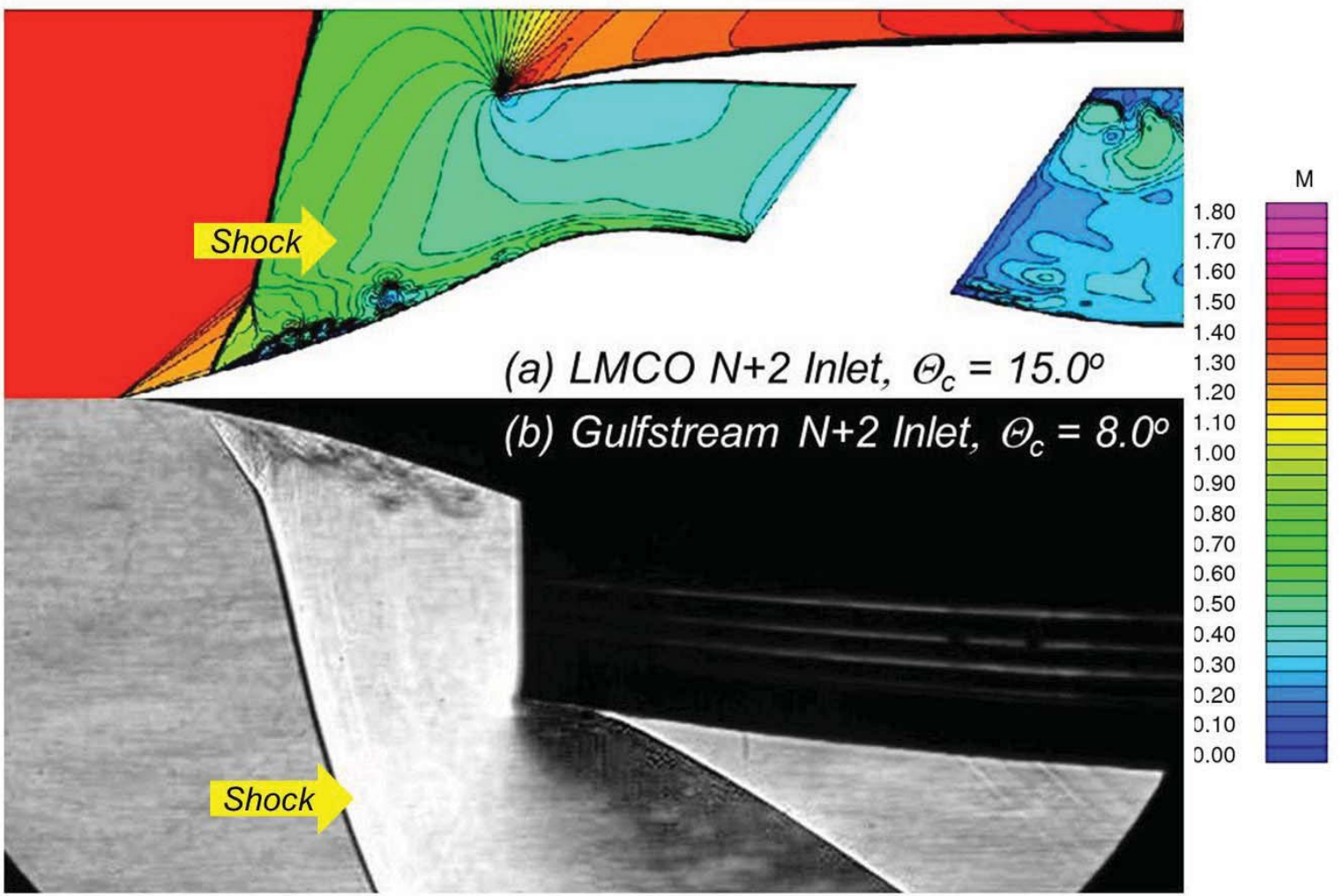

Figure (18): Comparison of CFD analysis and Schlieren photograph during buzz cycle, $\Delta t=4.3 \times 10^{-3} \mathrm{sec}$. 